\title{
INTERNETÊS: AMEAÇA À OU EVOLUÇÃO NA LÍNGUA PORTUGUESA?
}

\section{NETSPEAK: A THREAT OR PORTUGUESE LANGUAGE EVOLUTION?}

\author{
Fabiane Sarmento Oliveira Fruet \\ Paula Gaida Winch \\ Daiane Fagan \\ Ana Paula Zemolin
}

RESUMO: Este estudo trata da formação de um novo dialeto, o internetês, surgido a partir da revolução tecnológica da internet. Buscamos, em estudiosos da língua portuguesa, referências para subsidiar a discussão sobre o fato de o internetês representar ameaça a ou ser evolução dessa língua. Compreendemos que a criação e utilização desse dialeto constituem-se em uma representação do contexto sócio-histórico em que estamos inseridos.

PALAVRAS-CHAVE: língua portuguesa, novo dialeto, internetês.

ABSTRACT: This study deals with the formation of a new dialect, Netspeak, which originated in the internet technological revolution. We have sought references, in Portuguese language research, to support the discussion whether Netspeak represents a threat or language evolution. We have pointed out that the invention and use of the dialect are a representation of the social-historical context in which we are inserted.

KEYWORDS: Portuguese language, new dialect, Netspeak.

\footnotetext{
* Especialista em Tecnologias da Informação e da Comunicação aplicadas à Educação (UFSM) e Mestranda em Educação (PPGE - UFSM). faby@ mail.ufsm.br

${ }^{* *}$ Mestre em Educação (PPGE - UFSM).pgwinch@yahoo.com.br

*** Especialista em Letras - Literatura Brasileira (UNIFRA). daianefagan@ mail.ufsm.br

**** Graduada em Letras Português Licenciatura Plena (UFSM).apzemolin@ mail.ufsm.br
} 



\section{INTRODUÇÃO}

Esta pesquisa trata-se de um estudo teórico que tem por objetivo demonstrar como a Língua Portuguesa está em constante processo de transformação, bem como apresentar subsídios que conduzam a uma reflexão crítica sobre a consideração do internetês como ameaça à nossa língua ou como parte de um processo evolutivo da mesma, a partir da opinião de falantes e estudiosos do Português.

Ressaltamos que o uso do termo evolução, neste estudo, não está associado à emissão de juízo ou conotação positiva. Adotamos esse termo para designar um "processo de mudanças graduais e coerentes", conforme definido por Mattoso Câmara (apud FIORIN, 2007).

Para tanto, centramos nosso estudo na linguagem utilizada no espaço virtual, considerando que essa linguagem, por propagar-se e modificarse em curtos intervalos de tempo, resultou em um novo dialeto em nossa língua - o internetês ou netspeak, conforme termo empregado pelo linguista britânico David Crystal, para fazer referência a formas inéditas de expressão escrita criadas por usuários da internet.

Esse dialeto, internetês, está adquirindo grande relevância como linguagem utilizada em espaço virtual para fins comunicativos, pois, desde 1995, quando surgiram os primeiros provedores de acesso à internet, esse espaço tornou-se um novo segmento em nossa sociedade, sendo criados inúmeros dispositivos de comunicações, visando trocas de mensagens, receitas, fofocas, confidências pessoais, entre outras. 
Para efetivar este estudo, primeiramente, retomamos algumas concepções de língua expressas por estudiosos da área. Em segundo lugar, buscamos exemplos do dialeto internetês em blogs e salas de bate-papo virtuais e, por último, levantamos algumas opiniões sobre as mudanças na linguagem apresentadas nesse novo dialeto.

\section{CONCEPÇÕES DE LÍNGUA}

Algumas concepções de língua podem auxiliar-nos no entendimento da língua como estando em constante processo de mudança e, nessas concepções, também são mencionadas justificativas para tais mudanças.

Para Ferreira (1994), a língua é um "produto social" resultante da posição social e histórica ocupada pelo falante, não podendo ser reduzida a um sistema de signos organizados por uma gramática. O fato de ser considerada produto histórico e social resulta na necessidade de se ter consciência de que constantemente estará suscetível a mudanças.

Nesse sentido, a analista de discurso Orlandi (1996), explicita sua concepção de língua mediante relações entre língua, identidade, sujeito e nação. Para este estudo, faz-se relevante abordar a relação entre sujeito e língua, pois mediante o discurso de um sujeito é possível identificar traços de sua identidade, assim como do contexto em que ele está inserido ao proferir o discurso. Dessa forma, a linguagem altera-se de acordo com mudanças no contexto histórico, social e cultural e também conforme a maneira com que cada falante se expressa, observando-se que não há uma homogeneidade no discurso proferido por um indivíduo e por outro.

Já David Crystal expressa em seu livro A revolução da linguagem que a língua "está apoiada em um tripé: inglês como língua universal, a internet e a extinção em massa de línguas" (apud NOGUEIRA, 2006: 67). Por esses elementos mencionados pelo autor como influenciadores na linguagem, constatamos o dinamismo que envolve a língua.

Desse modo, há um caráter dinâmico atribuído à língua, ou seja, a língua evolui em paralelo às transformações sociais, históricas e culturais que ocorrem no espaço físico onde seus falantes estão inseridos, conforme verificamos na linguagem utilizada pela internet.

\section{O DIALETO INTERNETÊS}

É inegável que a disseminação da internet nas camadas mais altas da população brasileira, e em fase de popularização, vai criando uma nova forma de expressão, engenhosa, repleta de gírias, abreviaturas e palavras 
transpostas com significado claro, mas diferentes do registro formal da língua portuguesa. É assim que nascem os dialetos.

A internet quebrou as barreiras geográficas e culturais, e acabou criando, também, uma linguagem universal, um código que, muitas vezes, só os internautas conseguem decifrar. Quem entra na sala de bate-papo, escrevendo palavras com pontuações corretas e colocando os devidos acentos, acaba por denunciar que não pertence àquele grupo, ou seja, não está acostumado a utilizar a linguagem da internet.

Assim, as conversas nas salas de bate-papo se dão de maneira bastante informal, usando a língua escrita como código e, de certa forma, a língua falada como forma de expressão. Alguns exemplos práticos retirados de conversas e blogs estão expostos em seguida: $M s m$ - mesmo; $V c$ ou simplesmente $c$ - você; Oiiiii - Olá (a quantidade de is depois da letra $O$, em geral, é proporcional à alegria que a pessoa pretende demonstrar); Migoxxx - (cada $x$ representa o tamanho da amizade); Xeia - cheia; Naum - não; Ksa - casa; Bjo - beijo; Migona, miga, miguxa - amiga; Td - tudo ou todo; Mto - muito; Fds - fim de semana; Fotux - fotos; Gnt - gente; Aki - aqui; Qdo quando; $P q$ - por quê ou porque; Intaum - então.

Já existem manuais e glossários bastante razoáveis na internet (anexo), com expressões mais usadas em salas de bate-papo, blogs e fotoblogs, para simplificar a interlocução entre os mais ortodoxos e os falantes do novo dialeto. O princípio básico do internetês é extrair o essencial de cada palavra, descartar o supérfluo e, inevitavelmente, ceder à tentação dos apelos fonéticos. Isso se dá pela necessidade de tornar a comunicação mais ágil e veloz, tal como é na língua falada. Isso resulta em uma economia nas construções linguísticas empregadas no meio virtual.

É claro que o internetês poderá tornar-se mais padronizado no futuro; mas, atualmente, ainda está sofrendo alterações gráficas. Vogais, por exemplo, são quase dispensáveis, uma vez que algumas das consoantes carregam em si mesmas o som vocálico. É quando depende vira $d p n d$, também vira tbm e certeza vira ctza. Há também palavras que sofrem uma transformação onomatopeica, imitando o som ou a pronúncia do objeto, como, por exemplo, buáááááá (simulando o choro). Quando os internautas querem demonstrar uma risada ou gargalhada, eles fazem uso de diversos recursos, por exemplo, hihihihihi ou heheheh... ou hahahah... ou ainda eh,eh,eh. Outro componente da linguagem dos internautas são os Emoticons, que são símbolos que representam os sentimentos e o tom de quem está falando. 
Nessa minimalização linguística, outra prática comum é substituir dois por um: $q u, c h$ e ss se transformam em $k, x$ e $c$ (eskecer, xegar, ece). Meninas, a quem o Xou da Xuxa marcou pela eternidade, consideram que o som da letra $x$ é "meigo" - daí escolherem, em vez de $v c$ (para quem não sabe, o equivalente a você), $v x$. Acentos, evidentemente, são raríssimos; quando são absolutamente necessários, viram uma letra (por sinal, a única situação em que a palavra aumenta de tamanho).

A indicação de acento agudo é a letra $h(a h i, j a h, e h)$. Aqui, comprovamos a criatividade dos internautas; afinal, uma letra que nunca teve valor fonético em nossa língua torna-se essencial para demarcação do sentido da palavra. Por exemplo, é diferente quando escrevemos ai e aih, sem o $h$ evidencia-se uma expressão de dor, já com o $h$, temos uma expressão que indica lugar. O mesmo ocorre com a vogal $e$, sem o "acento" $h$ ela é simplesmente uma conjunção, e com o "acento", torna-se verbo.

$\mathrm{O}$ til, desfigura-se na expressão aum (naum para não, entaum para então). Nada disso garante que dois interlocutores cibernéticos vão se entender perfeitamente, visto que o dialeto da internet tem uma dinâmica própria e varia conforme a "tribo" ou a região do país.

\section{INTERNETÊS: LINGUAGEM DOS INTERNAUTAS}

O que caracteriza a linguagem dos internautas é a expressividade, a forma despreocupada com que usam e abusam da língua escrita, sem se importarem com as normas rígidas da língua escrita-formal. Isso faz com que os interlocutores se expressem de modo o mais informal possível, fazendo com que a língua escrita usada por eles, no momento da conversação, se pareça bastante com a linguagem coloquial.

Nessa nova forma de comunicação, os internautas utilizam uma gama enorme de recursos da própria linguagem escrita, obtendo um resultado bastante satisfatório e comunicativo. Além disso, eles, nas conversações em tempo real, não dispõem de tempo para fazer um planejamento prévio de seu discurso. Assim, a troca de mensagens tem de ser rápida, sem perda de tempo, fazendo com que eles tenham que criar abreviações, símbolos e sinais que tornem mais rápida a comunicação. Portanto, podemos observar que a comunidade dos internautas tem sua linguagem particular, ou seja, eles acabaram criando a sua variante de língua, a sua forma de se comunicar, que, de certo modo, assusta aquelas pessoas que não tem acesso ao "ciberespaço". 
Esta informalidade e a forma descontraída com que os internautas costumam se comunicar entre si são a marca principal de seu estilo. Por exemplo, “O que foi??????”, o internauta, com essa sucessão de interrogações, desejou, enfaticamente, expressar sua pergunta ao interlocutor como uma forma de espanto. Outra situação utilizada pelo internauta, para demonstrar um grande apelo, é usar letras maiúsculas "ALGUÉM TC CMG, POR FAVOR???????".

O dialeto da internet é diferente da língua escrita e da língua oral. Não temos ainda uma classificação específica, por ser muito recente, sendo que se constitui de uma mistura de ambas. Trata-se de um gênero híbrido. Para Jonsson (1997), o chat, em virtude da alta interatividade e da velocidade de troca de mensagens, é a forma de comunicação usada por computador em que é mais explícita a semelhança entre a escrita e a conversação oral. Os jovens se expressam mediante este novo dialeto, derivado do idioma português, principalmente, em salas de bate-papo, através de comunicadores instantâneos e e-mails. Porém, ao lermos suas redações, percebemos como o dialeto em questão penetra fundo no psiquismo do jovem, fazendo com que, por vezes, se confunda entre o registro culto do idioma e as expressões que ele utiliza entre amigos.

Outro meio em que podemos observar essa ocorrência é no canal Telecine, no qual os filmes da sessão Cyber Movie foram legendados de acordo com esse dialeto. $\mathrm{O}$ objetivo do Telecine é atingir pessoas que não gostam de filmes legendados e, consequentemente, de ler. Isso vem para agilizar o processo de leitura e dar ao espectador a oportunidade de prenderse mais às imagens. No entanto, os idealizadores do programa, conforme afirma Pinho (2005), estão preparados para as críticas. A mais contundente seria sobre o desuso da língua portuguesa. Porém, o diretor-geral do canal, João Mesquita, argumenta que "reproduzimos o jeito de falar dessa geração. Acreditamos estar contribuindo para a cultura." (apud PINHO: 56).

Percebemos que nos meios mais formais, como empresas, a necessidade de agilidade nas comunicações ainda não se dá a partir do uso desse dialeto. No entanto, em 2001, conforme estudos realizados na UFPE pela linguista Cilda Palma, referenciados na revista Veja (cf. TEIXEIRA, 2007), as mudanças nas comunicações internas, em espaço profissional, referiamse aos gêneros textuais utilizados para fins burocráticos, sendo que as cartas comerciais tradicionais começavam a ser substituídas pela comunicação via $e$-mail. 


\section{OPINIÕES SOBRE AS MUDANÇAS QUE ESTÃO OCORRENDO NA LÍNGUA COM A PROPAGAÇÃO DO INTERNETÊS}

O novo dialeto, internetês, tem dividido opiniões entre os falantes e estudiosos da língua portuguesa. De acordo com o escritor Deonísio da Silva (2005), em artigo publicado no site Observatório da Imprensa, esse novo "idioma" é um "besteirol" que "assassina" a tecladas a língua portuguesa. Silva defende essa ideia porque, para ele, os adolescentes têm acesso à internet, mas muitos deles não dominam a norma culta dessa língua. Por isso, ele acredita que o internetês é um sintoma da grave falência educacional, que por sua vez gera a exclusão dos jovens ao mundo letrado em que poucos têm acesso.

Compartilhando desse ponto de vista, encontramos fragmentos no texto de Jerônimo Teixeira (2007) que representam fortes críticas ao modo como a linguagem tem sido utilizada no espaço virtual. Reproduzimos aqui um dos fragmentos: "Embora a língua sofra ataques deformadores diários nos blogs e chats, a palavra escrita nunca foi usada tão intensamente antes." (p. 1).

Notamos a insatisfação quanto ao uso do internetês a partir do léxico escolhido pelo autor - "sofra ataques deformadores" -, geralmente utilizado com conotação negativa.

Junto a estes e outros posicionamentos contrários ao internetês, é reafirmada a existência de uma relação direta entre ser bem sucedido profissionalmente e ter domínio da norma culta padrão da língua, conforme mencionado também por Teixeira: "Dominar a norma culta de um idioma é plataforma mínima de sucesso para profissionais de todas as áreas”. (p. $1)$.

Nessa relação, o internetês aparece como um meio capaz de dificultar que as pessoas tenham sucesso na profissão, por afastá-las e estimulá-las a fazer uso de uma linguagem fora da norma culta.

Por outro lado, para os linguistas, a escrita cibernética é mais uma forma de comunicação, porque, segundo Eni Orlandi' (1996: 57), "os jovens estão crescendo nessa linguagem funcional. Se eles usam um meio eletrônico é porque querem ser rápidos. Não vejo perigo."

Nessa mesma linha, Marisa Lajolo (apud HANSEN), em programa de televisão exibido pela TVE, é uma das que não percebe como grave a invenção dos adolescentes. Ao contrário, ela acredita que a nova escrita

\footnotetext{
${ }^{1}$ Professora do Instituto de Estudos da Linguagem da Unicamp.
} 
na internet está promovendo um "surto de poliglotas". Na sua opinião, o internetês é apenas mais uma linguagem usada pelos jovens, para se comunicarem entre si, considerados, por ela, poliglotas pela capacidade de se expressar de maneira diferente com seus pais, professores e com os demais interlocutores da comunidade. Assim, para a escritora, isso demonstra a criatividade dos adolescentes em criar um código próprio, que reforça a identidade dos mesmos.

Nesse mesmo programa, Sérgio Nogueira aconselhou os professores a não ficarem assustados com esse novo dialeto, mas que eles procurassem conhecer essa linguagem. Pois, de acordo com Nogueira, seria interessante promover, em sala de aula, atividades com o dialeto, porque essas experiências têm a qualidade de reconhecer o fenômeno e explorá-lo, mostrando sua dimensão real, sem diminuir sua importância ou atribuirlhe poderes para ameaçar a língua portuguesa. Para alguns professores de metodologia de língua portuguesa não se deve aceitar que a linguagem da internet contamine a linguagem formal de maneira abusiva. Assim, segundo Marcos Nogueira (2006), o problema maior a ser atacado pelos professores é mesmo o domínio da língua padrão.

Na mídia impressa, também houve manifestações. Em sua página na revista $O$ Globo (20/3/2005), a escritora gaúcha Martha Medeiros escreveu sobre o internetês e se mostrou assustada com a adoção do dialeto no lançamento do Cyber Movie. Para ela, esse é um sinal de "lamentável e vertiginosa decadência da língua portuguesa" (apud HANSEN, 2005).

\section{CONSIDERAÇÕES FINAIS}

A partir desse levantamento de concepções de língua, de exemplos do uso do internetês, bem como de opiniões de estudiosos a respeito das mudanças que estão ocorrendo na língua portuguesa, principalmente em relação ao dialeto internetês, percebemos o constante processo de transformação que a língua está submetida e que esse processo é um "fenômeno natural", não podendo ser controlado. Então, ao invés de irmos contra o uso desse dialeto, conforme expresso por Silva (2005) e Medeiros (2005), devemos aprender a utilizá-lo de forma que ele não represente uma ameaça para a língua portuguesa padrão.

Desse modo, nosso posicionamento frente a esse dialeto vai ao encontro da afirmação de Bechara, porque, segundo o filólogo, "enquanto essa grafia cifrada for usada somente em ambiente de internautas, tudo bem, é mais uma modalidade gráfica de gíria. Extrapolar isso ao grande público é um 
assalto à integridade do idioma." (apud PINHO, 2005: 57). Pois uma coisa é usar o internetês na informalidade e com amigos, outra é utilizá-lo para toda comunicação.

É preciso estabelecer limites, ter bom senso e saber o momento correto de utilizar esse código. Tudo é uma questão de adequação, não podemos adotar o internetês como único recurso escrito, justamente por ser muito simplificado e quase sem regras gramaticais. $O$ uso desse tipo de linguagem seria inadmissível, por exemplo, em um trabalho dissertativo, em um ofício, em uma redação, pelo menos nos padrões linguísticos de hoje. Assim, os usuários desse dialeto devem policiar-se para não usarem a língua da internet em trabalhos e documentos importantes.

Tendo em vista essa rápida propagação do internetês, concluímos que o surgimento desse dialeto comprova a vitalidade da língua e sua capacidade de se transformar através das gerações, pois ela se mantém viva devido aos "fascinantes mecanismos que a transformam constantemente" (NOGUEIRA, 2006: 62). Devemos considerar a evolução da língua, admitindo, assim, a criação de novos dialetos.

Compreendemos que a criação e a utilização desse dialeto constituemse em uma representação do contexto sócio-histórico em que estamos inseridos, marcado por mudanças tecnológicas, fácil acesso à informação e também pela valorização da praticidade no dia-a-dia, principalmente, ações práticas e objetivas em relação à comunicação e à linguagem utilizada.

Com as devidas ressalvas e cuidado com a adequação linguística, o internetês pode ser considerado como uma evolução em nosso sistema linguístico e não deve ser visto como uma ameaça. Não podemos associar mudança na língua com degeneração, declínio ou decadência; mas sim como um processo natural resultante de uma série de fatores sociais.

\section{ANEXO \\ GLOSSÁRIO DAS EXPRESSÕES MAIS USADAS EM SALAS DE BATE-PAPO}

\section{Simplificações mais comuns na língua portuguesa}

* "Qu" transforma-se em "k" ou "ku", dependendo da palavra:

o Quatro: kuatro; Aqui: aki; Quem: kem; que = q ou ke.

* "Ch" transforma-se em " $\mathrm{x}$ ", tal como palavras com dois " $\mathrm{s}$ " seguidos:

o chocolate: xocolate; achar: axar; passar: paxar; nossa: noxa; assassino: axaxino; 
Outras simplificações possíveis são as de palavras muito usadas, tais como:

* com torna-se cm, c ou c/;

* quando torna-se kdo, qdo ou qd;

o quando nunca se torna em kd, que é uma forma encurtada de cadê;

* quanto em kto ou qto;

* donde torna-se dd;

* comigo torna-se cmg;

* mais torna-se + ;

* menos torna-se -;

* para torna-se $\mathrm{p} /, \mathrm{pr}$ ou pa;

* beleza torna-se blz;

${ }^{\star}$ não torna-se ñ, $\mathrm{n}$ ou naum;

* Também torna-se tbm ou tb;

* Teclar torna-se tc, que é uma gíria para "conversar usando o teclado";

* Como torna-se cmo.

Palavras e frases muito usadas pelas pessoas

* Kd vc? que significa "Cadê você?"

* Flw que significa "Falou"

* $\mathrm{T}+$ que significa "Até mais"

* Oq que significa "O quê"

* Vc que significa "Você"

${ }^{\star} \mathrm{C}$ que significa "Se"

*Vlw que significa "Valeu"

* Eh que significa "É"

* Mto que significa "Muito"

* blz que significa "Beleza"

* $\mathrm{Tb}(\mathrm{m})$ que significa "Também"

* + que significa "Mais"

* - que significa "Menos"

* qm que significa "Quem"

* tah que significa certo, tudo bem, e outras variantes

* FTW, sigla de "For the win", que mostra apoio.

* tou que significa "Estou"

* AFK Away From Keyboard ou longe do teclado.

* Aski que significa "Acho Quê" 


\section{Emoções humanas}

As emoções humanas (emoticons) são expressas por vários caracteres disponíveis no teclado. Os símbolos mais comuns são:

\begin{tabular}{|c|c|}
\hline :-) ou :) & sorrindo \\
\hline$:-($ ou $:($ & triste \\
\hline$:-/$ ou :-\ou :\ou :/ & indeciso \\
\hline$:-\mid$ & incerto \\
\hline ;-) ou ;) & piscadela (piscada) \\
\hline :-D ou :D ou =D & sorriso grande ou risada \\
\hline :-P ou :-p ou :P & de língua para fora, expressando sarcasmo \\
\hline B-) ou 8-) & com óculos escuros \\
\hline :-o ou :-O ou $=0$ & surpreso \\
\hline :-S ou :-S ou $=S$ & confuso \\
\hline$:-\mathrm{x}$ & "Eu não deveria ter dito isso" (ou beijo) \\
\hline$: '-($ ou : - ( ou :,-( & chorando \\
\hline :o) ou :O) & nariz de palhaço \\
\hline$>:-)$ ou $\}:-)$ & diabólico (com chifres) \\
\hline$x)$ ou $x D$ & $\begin{array}{l}\text { rindo, com os olhos fechados (ou envergonhado). Há } \\
\text { muitas polêmicas em relação a origem do "xD", mas } \\
\text { ela foi tirada dos animês (desenhos japoneses) sendo } \\
\text { então marca registrada de Otakus (pessoas que gostam } \\
\text { de animês e cultura oriental). }\end{array}$ \\
\hline 5:) & topete \\
\hline :D ou :-D ou =D & muito contente \\
\hline$:^{*}$ ou $=^{*}$ & beijinho \\
\hline$\wedge \_\wedge$ ou $\wedge \wedge$ ou $\wedge . \wedge$ & versão oriental de sorriso \\
\hline$+\ldots$ ou X_ & versão oriental de chocado ou triste \\
\hline O_O ou 0.0 & versão oriental de assustado \\
\hline O_o ou o_O ou O.o ou o.O & estranhando algo \\
\hline O:-) & santo ou "não fiz nada" \\
\hline.$/ \mathrm{ou}_{-} \mathrm{l}_{-}$ & gesto obsceno \\
\hline ᄀר & emoticon oriental do "olhar de lado" \\
\hline :] ou :-] ou =] & sorriso simples, "quadrado" ou sem-graça. \\
\hline$: \wedge)$ & nariz grande ou nariz pontudo \\
\hline @.@ou@_@ & modo oriental de muito confuso \\
\hline T.T ou T_T & modo oriental de choro \\
\hline TT.TT ou TT_TT & modo oriental de muito choro \\
\hline :@ou :-@ & raiva \\
\hline
\end{tabular}


Um caso especial é LOL, que significa rir, e provém do acrónimo inglês para "Laugh Out Loud" (ou seja, Rir Bem Alto - gargalhar). Para alguns, o lol parece com uma pessoa com os braços erguidos, ou ainda uma boca aberta rindo. No Brasil, usa-se "hahuaheuahua", "aUAheUHEAUehaeuhaeuAH", "KKKKKKKKKKKK" ou "rssssss" (todos com diversas variações, apesar dos dois últimos tipos serem polêmicos, por causa da sociedade KKK e da abreviação do Estado do Rio Grande do Sul), bem como o "eheheh", também com sentido de riso, tanto no Brasil quanto em Portugal.

\section{Gritar}

Ainda relacionado com a expressão das emoções humanas, para "gritar" no internetês utiliza-se caixa alta nos textos como em: "EI! VOCÊ! PARE JÁ ONDE ESTÁ!" - geralmente isso é considerado falta de educação ou significa que o interlocutor perdeu o controle sobre a razão.

Disponível em: http://pt.wikipedia.org/wiki/Internet\%C3\%AAs. Acesso em: 10 fev. 2009.

\section{REFERÊNCIAS BIBLIOGRÁFICAS}

FERREIRA, Carlota; CARDOSO, Suzana Alice. A dialetologia no Brasil. São Paulo: Contexto, 1994.

FERREIRA, Maria Cristina Leandro (Org.). Glossário de termos do discurso. Porto Alegre: UFRGS. Instituto de Letras, 2001.

HASEN, Karla. Internetês: uma ameaça à Língua Portuguesa. 11 abr. 2005. Disponível em: <http://www.educacaopublica.rj.gov.br/jornal/ materia.asp?seq=227> . Acesso em: 16 mar. 2006.

JONSSON, Ewa. Eletronic Discourse: on Speech and Writing on the Internet. 1997. Disponível em: <http://www.ludd.luth.se/users/jonsson/ Dessay/eletronicdiscourse.html>. Acesso em: 10 out. 2002.

NOGUEIRA, Marcos. A língua solta. Superinteressante, p. 62-67, abr. 2006.

ORLANDI, Eni Puccinelli. Interpretação: autoria, leitura e efeitos do trabalho. Petrópolis, RJ: Vozes, 1996. 
PINHO, Cláudia. Haja kbça p/ tanta 9idade. Revista Isto é, p. 56-57, 16 mar. 2005.

SILVA, Deonísio da. Português assassinado a tecladas. 15 mar. 2005. site Observatório da Imprensa. Disponível em: http://observatorio. ultimosegundo.ig.com.br/artigos.asp?cod=320JDB001>. Acesso em: 05 fev. 2008.

TEIXEIRA, Jerônimo. Riqueza da língua. Revista Veja, 12 set. 2007. Disponível em: <http://veja.abril.com.br/120907/p_088.shtml >. Acesso em: 05 fev. 2008. 